\title{
Imaging CFTR in its native environment
}

\author{
Hermann Schillers
}

Received: 7 October 2007 / Accepted: 9 November 2007 / Published online: 5 December 2007

(C) Springer-Verlag 2007

\begin{abstract}
Application of atomic force microscopy (AFM) on isolated plasma membranes is a valuable method to study membrane proteins down to single-molecule level in their native environment. The cystic fibrosis transmembrane conductance regulator (CFTR), a protein of the adenosine triphosphate-binding cassette transporter superfamily, is known to play a crucial role in maintaining the salt and water balance on the epithelium and to influence processes such as cell volume regulation. A mutation in the gene encoding for CFTR results in cystic fibrosis (CF), a very common lethal genetic disease. Identification of CFTR within the cell membrane at the single-molecule level makes it feasible to visualize the distribution and organization of CFTR proteins within the cell membrane of healthy individuals and $\mathrm{CF}$ patients. We were able to show that human red blood cells have a CFTR distribution comparable to that of epithelial cells and that the number of CFTR in cells derived from CF patients is strongly reduced. Studies on CFTR-expressing oocytes disclose CFTR dynamics upon CFTR activation. We observed that cyclic adenosine monophosphate induces an insertion of CFTR in the plasma membrane and the formation of heteromeric CFTR-containing structures with yet unknown stoichiometry. The structure of CFTR was identified by highresolution scans of immunogold-labeled CFTR, revealing that CFTR forms a tail-to-tail dimer with a central pore. In conclusion, these studies show that AFM experiments on isolated plasma membranes allow not only quantification
\end{abstract}

H. Schillers $(\square)$

Institute of Physiology II, University of Muenster,

Robert-Koch-Str. 27b,

48149 Muenster, Germany

e-mail: schille@uni-muenster.de and localization of membrane proteins but also provide insight in their dynamics at a single-molecule level.

Keywords Membrane - Chloride channel - Xenopus laevis . Cystic fibrosis · Erythrocytes · Cystic fibrosis transmembrane conductance regulator

\section{Introduction}

The plasma membrane of the cell accommodates diverse membrane proteins, including integral membrane proteins such as receptors, ion channels, and transporters, as well as certain antigens that are peripherally associated with the membrane. Because of their important roles in cell growth, differentiation, and cell-cell signaling, the structures of the plasma membrane and the proteins associated with it have attracted wide attention and have been extensively investigated. Cell membranes separate the cell interior from the extracellular space by using a lipid bilayer. The fluid mosaic membrane model, published by Singer and Nicolson 35 years ago [92], described the cell membrane as a twodimensional oriented solution of integral proteins in the viscous phospholipid bilayer. It predicts lateral and rotational freedom and random distribution of molecular components in the membrane. Now, however, it is known that this freedom of protein mobility is anything but unrestricted. Observations that membrane proteins diffuse in a way that indicates lateral heterogeneity in membrane structure [35] led to the perception that the membrane is a heavily compartmentalized, quasi-two-dimensional structure, which is more mosaiclike than fluid [104]. Several techniques are available to investigate the heterogeneity of cell membranes, but they show limitations in terms of resolution or artificial conditions. For biochemical approaches, membranes are usually 
fractionalized [22], and therefore the arrangement of proteins and membrane domains are hardly observable at the scale of a cell. A single-molecule approach provides considerable advantages, as it removes the data-averaging drawback inherent in biochemical techniques that record measurements over large ensembles of molecules. Fluorescence microscopy is applicable under physiological conditions, but the resolution is limited by the Rayleigh criterion to $240 \mathrm{~nm}$ [6]. Electron microscopy provides high resolution but needs sample coating and high vacuum conditions. Atomic force microscopy (AFM), however, allows high-resolution imaging under physiological conditions. This allows the study of functional changes in structure as shown, e.g., for nuclear pores [17, 68, 69, 81, 91] and endothelial cells [66, 87].

Because AFM provides structural data, a combination of AFM with immunostaining is necessary to allocate a specific protein within the membrane, as was shown for membrane receptors $[20,71]$ and ion channels $[31,93]$.

\section{Cystic fibrosis transmembrane conductance regulator}

The cystic fibrosis transmembrane conductance regulator (CFTR) is a cyclic adenosine monophosphate (cAMP)activatable membrane protein that acts not only as an ion channel but also as a regulator of several membrane conductances [89]. However, the specific mode of action is still unclear. Currently, several models are discussed, e.g., direct protein-protein interaction [42], autocrine signaling [9], and modulation of endo- and exocytosis [7]. An individual CFTR molecule exhibits two hydrophobic core regions, each with six membrane-spanning domains and two nucleotide-binding folds (NBDs). A large cytoplasmic regulatory domain (R-domain) connects the two halves of the CFTR molecule [75]. CFTR is a chloride channel that is activated by phosphorylation of the R-domain via cAMPactivated protein kinase A and adenosine triphosphate (ATP) binding/hydrolysis at the NBDs $[23,26]$. A mutation in the gene encoding for CFTR results in the severe disease of cystic fibrosis (CF). The most common CF-associated mutation is deletion of phenylalanine at residue 508, $\triangle$ F508 CFTR. CFTR bearing the $\Delta$ F508 mutation fails to progress through the normal biosynthetic pathway and fails to traffic to the plasma membrane. As a result, CFTR $\Delta$ F508 is mislocalized and is not present in the apical membrane of epithelia cells [111]. Consequently, the apical membrane of $\mathrm{CF}$ cells is $\mathrm{Cl}^{-}$impermeable resulting in an impaired electrolyte transport and fluid secretion by several epithelia, including the sweat duct, exocrine pancreas, and the pulmonary airways [25]. However, it was shown that the membrane distribution of $\triangle \mathrm{F} 508 \mathrm{CFTR}$ is tissue specific and exhibits variation of expression from null to apparently normal amounts $[18,39]$. Up to now, it is unclear if CFTR forms a multimer of two or more CFTR polypeptides or if a single CFTR shows the entire activity [74]. There is evidence for monomeric as well as for dimeric CFTR. Furthermore, CFTR, as a member of the ATP-binding cassette (ABC) transporter family, is assumed to form clusters with different proteins to fulfill its regulatory function $[1,28]$.

This review shall help to enlighten the questions about the membrane distribution of CFTR and its quaternary structure.

\section{Atomic force microscopy}

The operation principle of an AFM could be described as a sharp tip, mounted on a flexible cantilever, which raster scans a surface and thereby contours its profile. Prerequisite for a high resolution is a minimal interaction between the tip and the sample to prevent lateral displacements of sample structures. In addition, a hard sample is essential for submolecular resolution because this reduces vertical fluctuations. The tip geometry, which is usually an inverted pyramid, also influences the resolution. On a surface with considerable height differences, structures will interact not only with the very end of the tip but also with the tip flank. This so-called tip convolution results in a broadening of the structure in the image and thus reduces the lateral resolution [53]. Therefore, a flat sample with minimal height differences is necessary to obtain submolecular resolution. Another prerequisite for high resolution is a low mobility of the sample. Membrane proteins are important components of the cellular machinery and involved in many cellular processes. They are embedded in a plasma membrane and in many cases connected to the underlying cytoskeleton. This means that they are immobilized in their native environment, which allows imaging of individual proteins by AFM. Decidedly, the best sample for highresolution imaging is a crystal in which no lateral or vertical movement of sample structures occurs. Atomic resolution and even subatomic resolution was shown on a silicon surface [27].

\section{Imaging of membrane proteins in a $2 \mathrm{D}$ crystal}

AFM provides subnanometer resolution of protein structure in either densely packed amorphous or 2D crystal arrangements of proteins [95]. These samples fulfill the requirements for high-resolution scanning because they are hard, flat, and embedded in a densely packed array, which strongly reduces the lateral displacement of these proteins. Under optimal conditions, the best resolution achieved vertically is $\sim 0.1 \mathrm{~nm}$ and laterally $\sim 0.5 \mathrm{~nm}$, enabling the observation of structural details of single-membrane pro- 
teins [60]. Submolecular resolution was shown for several naturally occurring $2 \mathrm{D}$ protein crystals, e.g., OmpF (outer membrane protein F) porin from Escherichia coli [80], bacteriorhodopsin in purple membrane from Halobacterium salinarium [61], and the hexagonally packed intermediate layer from Deinoccocus radiodurans [59].

\section{Imaging isolated cell membranes}

The plasma membrane of eukaryotic cells is generally anything but flat. The curvature of a cell is formed by lamellopodia, cell body, and cell nucleus. The membrane shows major structures like membrane ruffles [8], microvilli, and cilia and also submembranous structures like the cytoskeleton [79]. Furthermore, a closer view reveals unevenness of the plasma membrane like humps and pits representing endo- and exocytotic activity [88]. A huge variety of proteins is heterogenic, distributed within the membrane, and many membrane proteins are equipped with highly branched sugars forming the glycocalix. The glycocalyx, a network of polysaccharides that protrudes up to $100 \mathrm{~nm}$ from cellular surfaces, limits the tip access to the membrane surface, thus reducing the resolution [46].

These factors revealed that a molecular resolution, indispensable for dissolving the quaternary structure of CFTR, cannot be achieved on whole cells. Therefore, we decided to isolate cell membranes on a solid support in such a way that the intracellular face of the membrane is accessible for the AFM tip ("inside-out" orientation). This approach offers several advantages: (1) The membrane is flat because of the fact that no curvature is imposed by underlying structures (e.g., nucleus, cytoskeleton), (2) the membrane is hard because it lies on a hard support instead of a soft cytosol, (3) the intracellular face of the membrane could be imaged by AFM, which means that no glycocalix disturbs high-resolution imaging. Indeed, this methodology will not allow the investigation of the external part of CFTR, and our results are strictly related to the cytoplasmic part of CFTR. Nevertheless, the applied method is appropriate because CFTR, as well as other membrane proteins, shows only a minor part of its polypeptide chain on the extracellular face, while the main portion is located intracellularly. We developed different techniques to isolate membranes from different cell types. The main principle is to "glue" the cell on a functionalized surface and subsequently remove the cell, whereby membrane patches remain in an inside-out orientation [65, 67]. The most suitable kind of surface modification and method of cell removal depend on the cell type. Ehrenhöfer et al. [19] glued the plasma membrane of Madin-Darby canine kidney (MDCK) cells with iberiotoxin, a positively charged toxin molecule that binds with high affinity to plasma membrane potassium channel to a mica surface. The membrane of MDCK cells was isolated by a patch pipette and transferred on freshly cleaved mica [45].

\section{CFTR in human erythrocytes}

CFTR is not only found in epithelia but also in human erythrocytes (red blood cells [RBC]) as shown by using Western blot techniques [96], in studies of plasmodium falciparum-induced channel activation [105], by deformation-induced CFTR-dependent ATP release [94] and functional studies [97, 98]. The membranes of RBC were isolated according to a modified method of Swihart et al. [100]. In short, RBC attached to poly-L-lysine-coated glass were sheared open with a jet stream of isotonic phosphatebuffered saline (Fig. 1a) [44]. The fluid mosaic model describes a cell membrane as a two-dimensional oriented solution of integral proteins in the viscous phospholipid bilayer. Current textbooks estimate a protein content of $50 \%$ for typical membranes [16]. This means that the lipid bilayer should be accessible for the AFM tip and therefore visible in the AFM images. High-resolution images of the $\mathrm{RBC}$ membrane show a dense layer of different protein structures but no lipids. Figure 2 shows a $5 \times 5$ - $\mu \mathrm{m}$ scan of the cytosolic face of a human erythrocyte. A dense package of proteins with different shapes and sizes impedes the view on the lipid bilayer. These observations are in good agreement to other AFM studies of human erythrocytes [112]. Tip convolution contributes but not exclusively to this view of the membrane. Either globular shapes of huge intracellular polypeptide chains or a protein content much higher than expected could cause this appearance of a human red cell membrane.

We used this membrane preparation to quantify CFTR on a single-molecule level in isolated RBC membranes from healthy donors (non-CF RBC) and from CF patients (CF RBC) with the homozygous $\Delta$ F508 mutation. In a first approach, we combined immunofluorescence using quantum dot (Qdot)-labeled antibodies with AFM. Qdots are crystalline fluorophores with an extreme photostability [4, $63,37,36,106]$, appearing as bright spots and as distinct fluorescence events on the membranes (Fig. 3a and b). Importantly, the images show drastically reduced fluorescence events for the samples from CF patients compared to non-CF membranes. We assume that the bright spots represent an accumulation of several Qdots because the resolution of fluorescence microscopy is too low to identify single Qdots within a particular bright spot. The crystalline nature of the Qdots, however, allowed single-molecule detection with AFM. In the AFM images, Qdots appear as structures with uniform height and shape (Fig. 3c and d). Because the AFM provided the required single-molecule 
Fig. 1 a Schematics of the membrane preparation. RBCs are exposed to fluid flowimposed shear stress and, as a result, the cells are open, exposing their cytoplasmic side of the membrane. AFM images of b RBCs attached to poly-Llysine-coated glass, $\mathbf{c}$ inside-out oriented RBC membrane patches spread on the glass surface after shear stress (modified from [44]). The heights are color coded with different scales for $\mathbf{b}$ and $\mathbf{c}$. The highest structures in $\mathbf{b}$ are up to $3 \mu \mathrm{m}$ (white) while overlapping membranes in c show heights up to $40 \mathrm{~nm}$ (bright yellow)
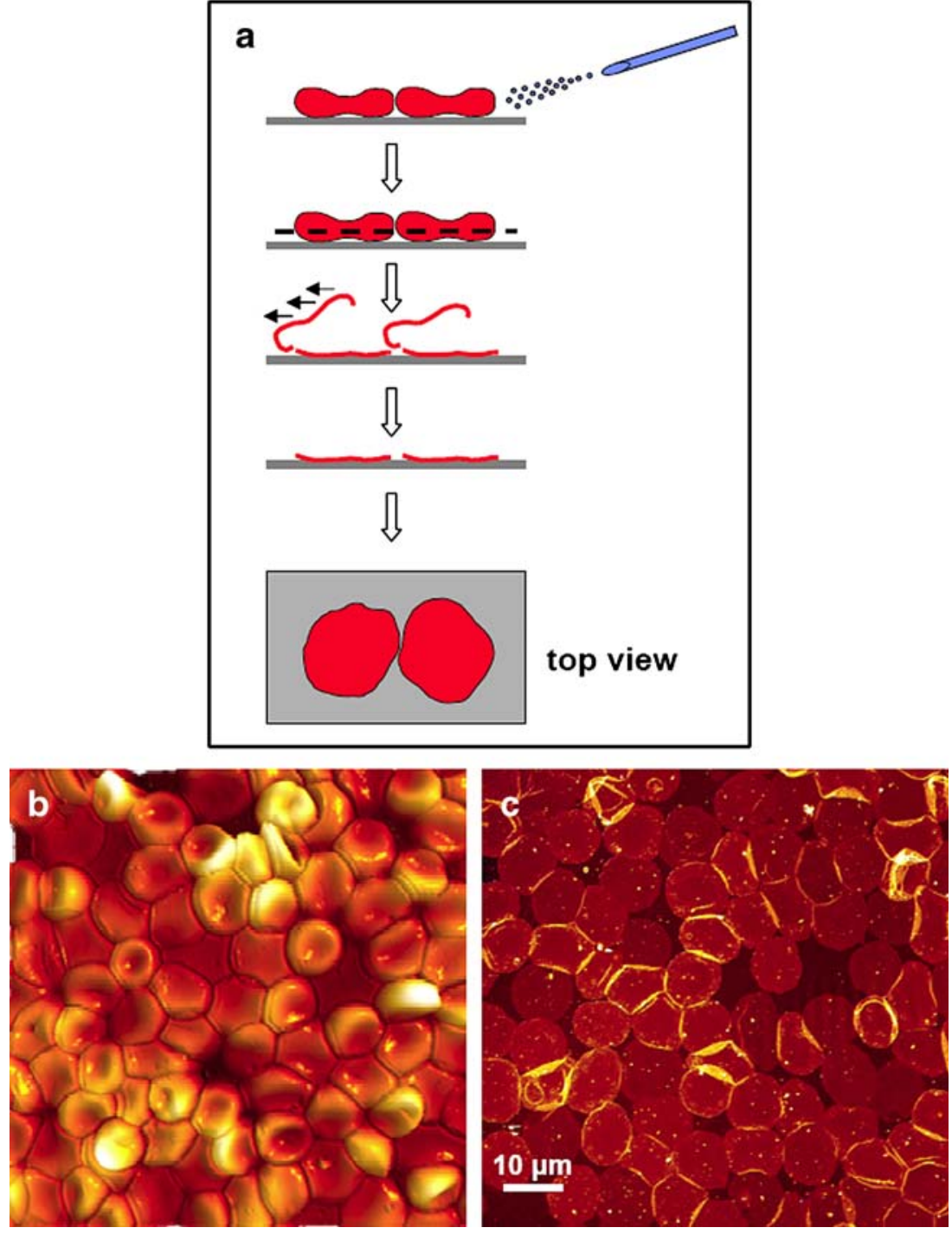

resolution for further detailed quantification of Qdot labeled-CFTR proteins at the RBC membranes, we used the images taken with AFM. Quantification of Qdots on non-CF RBC membranes revealed a mean value of about 650 CFTR molecules per RBC. In contrast, in CF patients, we found only about 200 CFTR molecules per RBC (Fig. 4). Assuming that each Qdot represents a single CFTR molecule, we could determine a CFTR density of $\sim 5$ CFTR per $\mu \mathrm{m}^{2}$ for non-CF RBC and of $\sim 1.6$ CFTR per $\mu \mathrm{m}^{2}$ for $\mathrm{RBC}$ from $\mathrm{CF}$ patients. The observed CFTR density of non-CF RBC is in good correlation to electrical measurements in Calu-3 cells, a human airway epithelial cell line [30].

In conclusion, our results demonstrate that RBCs have a CFTR distribution comparable to that of epithelial cells. Therefore, CFTR is suspected to play a physiological role in $\mathrm{RBC}$.

\section{Xenopus laevis oocytes membranes}

The Xenopus laevis South African frog oocyte is a wellsuited and widely used system for protein biochemistry and functional studies. We developed a method to isolate the plasma membrane of oocytes on a glass support to study membrane proteins and lipids by AFM [67, 83]. After removal of the vitelline membrane, intact oocytes are brought into contact with poly-L-lysine-coated glass and then rolled off. Inside-out-oriented plasma membrane patches left on the glass surface are first identified with the lipid fluorescent marker FM1-43 and then scanned by AFM. Examination of the samples by fluorescence microscopy reveals large patches with sharp edges of inside-outoriented plasma membrane, areas without membrane and bright spherical structures (Fig. 5). Membrane fragmentation occurs frequently because of the preparation method 


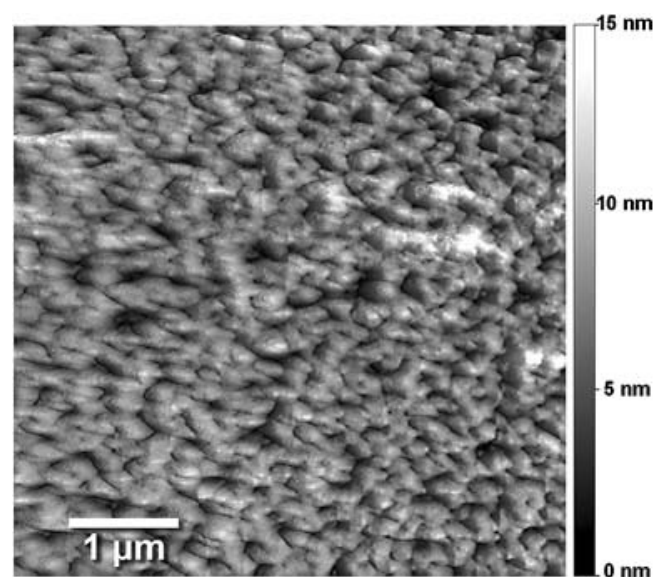

Fig. 2 High resolution scan $(5 \times 5 \mu \mathrm{m})$ of the cytosolic face of a human erythrocyte. The high protein density together with the tip geometry (tip convolution) almost prevents imaging the lipid bilayer between the proteins. However, at some points the lipid bilayer is visible defining the zero height in this image

we used. These membrane patches appear in AFM as layers with a high protein density protruding up to $20 \mathrm{~nm}$ into the intracellular space. Edges of membrane were used to determine total height of plasma membrane and its protruding structures. Figure 6 shows a 3D color-coded view of an area containing a plasma membrane fragment attached to the poly-L-lysine-coated glass surface. We used this specific color coding to emphasize the height differences between glass and membrane. This led to a poorer contrast for small protein structures. The profile along the broken line is shown in the lower part of Fig. 6. Basically, three different height levels can be determined: The first level is a height value of about $1.5 \mathrm{~nm}$ caused by poly-Llysine coating. The second level, indicated by a dashed line, corresponds to the 5 -nm height of the lipid bilayer. The third level represents the height of the proteins (up to $15 \mathrm{~nm}$ ) protruding from the inner surface of the plasma membrane. Proteins appear with different heights and shapes. The shape of protein structures embedded in the plasma membrane become more clear in higher magnifications. Figure 7 shows an $800 \times 800$-nm scan of the area of lower protein density (marked in Fig. 6). Some proteins apparently exhibit "shoulders"(white arrows), while others stand so close to each other that they overlap (black arrows). The lipid bilayer surrounds the proteins giving the impression that the lipids stick to the proteins. Because the plasma membrane height is $5 \mathrm{~nm}$, we cannot detect proteins smaller than $5 \mathrm{~nm}$, i.e., membrane-embedded proteins. To test whether protrusions emerging from the lipid membrane toward the cytoplasmic space were indeed proteins, we incubated membranes with the enzyme trypsin. About $5 \mathrm{~min}$ after incubation with $0.05 \%$ trypsin at room temperature,
Fig. 3 Immunostaining of CFTR in isolated RBC membrane patches with Qdot-labeled antibodies. The upper panel represents fluorescence images of non-CF (a) and CF (b) RBC membrane patches. Each inset shows a single membrane with clearly distinguishable bright fluorescence events. The lower panel shows AFM images of non-CF (c) and CF (d) RBC membrane patches. Highresolution scans, shown in $\mathbf{c}$ and d, identify the Qdot as high structures $(\sim 15 \mathrm{~nm}$, color code: white) with specific shapes. It is evident that the number of Qdotlabeled CFTR molecules is much higher in non-CF RBC than in CF RBC. (modified from Lange et al. [44])
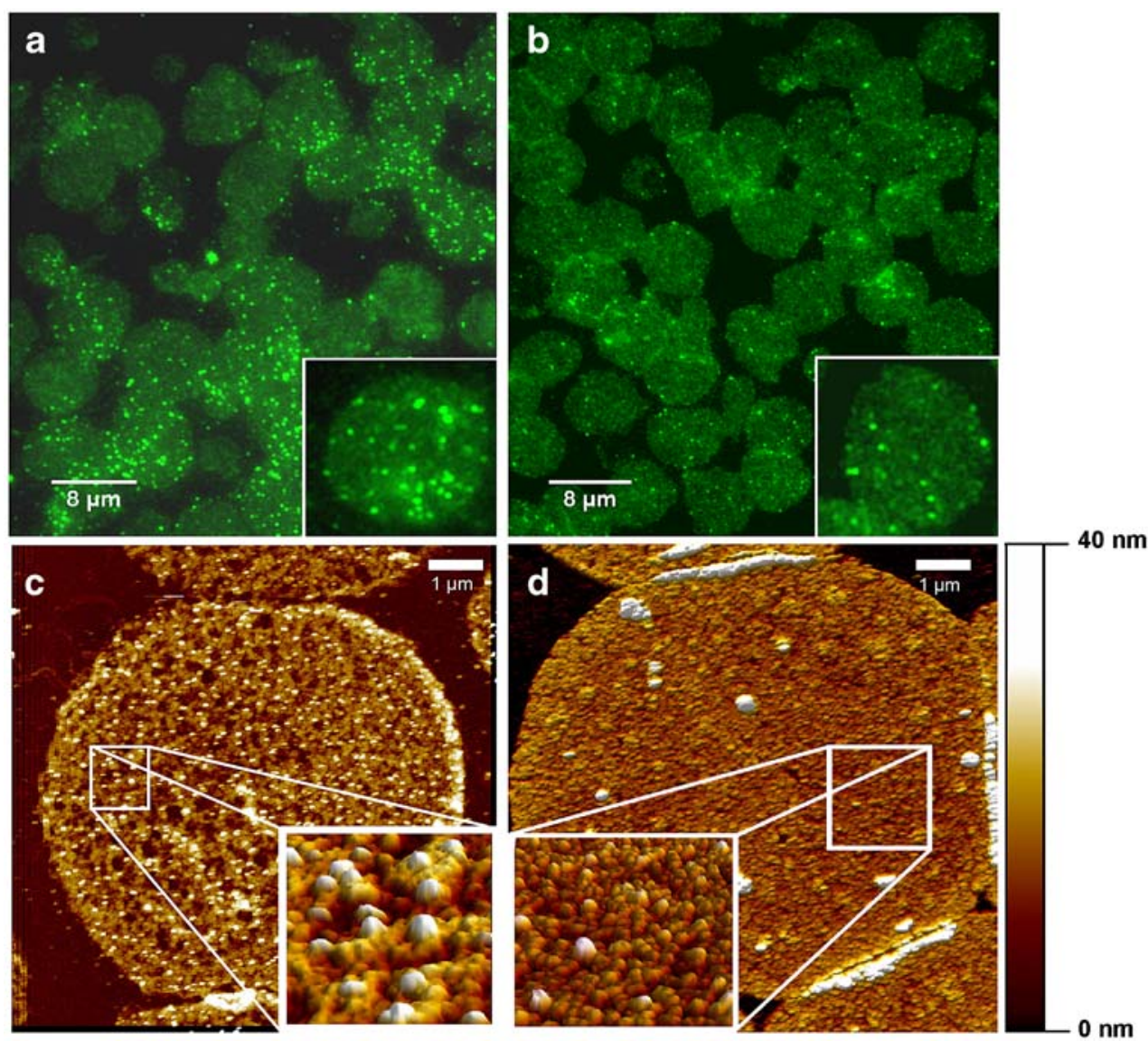


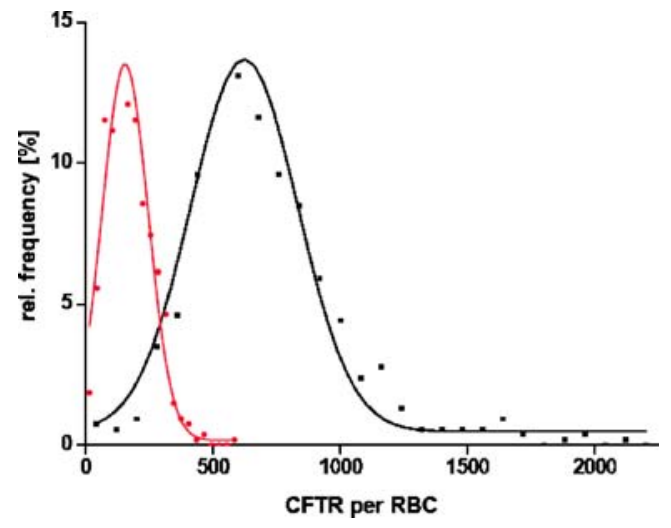

Fig. 4 Histogram of CFTR distribution on human red blood cells. Single molecule counting of Qdot-labeled CFTR molecules on RBC from five non-CF donors and five $\mathrm{CF}$ patients (100-120 RBC membrane patches from each individual) reveals a Gaussian distribution of CFTR within the RBC population. The histograms show peak values of 642 for non-CF-RBC (black curve) and 204 for CF-patients (red curve), respectively. The isolated membrane patches represent approximately $40 \%$ of the RBC membrane, and the results were extrapolated to the total RBC surface area of $130 \mu \mathrm{m}^{2}$ (modified from Lange et al. [44])

protruding structures are dramatically decreased in height. Profiles taken before and after trypsin treatment clearly indicate that protrusions are indeed proteins sensitive to trypsin digestion (data not shown). Surprisingly, we did not find cytoskeletal structures attached to the intracellular surface of the plasma membrane. We assume that binding between cytoskeletal structures and membrane proteins was disrupted during the process of membrane excision leaving behind the membrane proteins embedded in the lipid bilayer firmly attached to the coated glass surface. Nevertheless, we cannot exclude the possibility that membrane proteins firmly bound to cytoskeletal structures were pulled off the lipid bilayer leaving behind a membrane

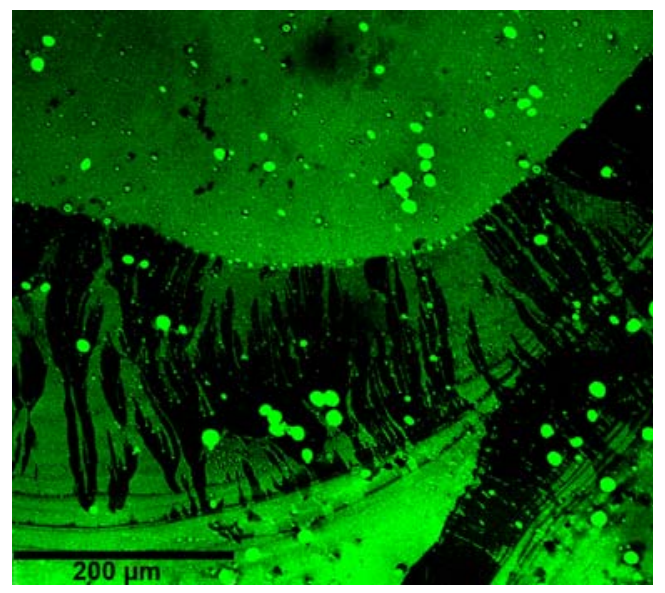

Fig. 5 Inside-out oriented plasma membrane patches from Xenopus laevis oocyte at the glass surface identified with the lipid fluorescent marker FM1-43. Fluorescence microscopy revealed large patches of inside-out-oriented plasma membrane, areas without membrane, and bright spherical structures
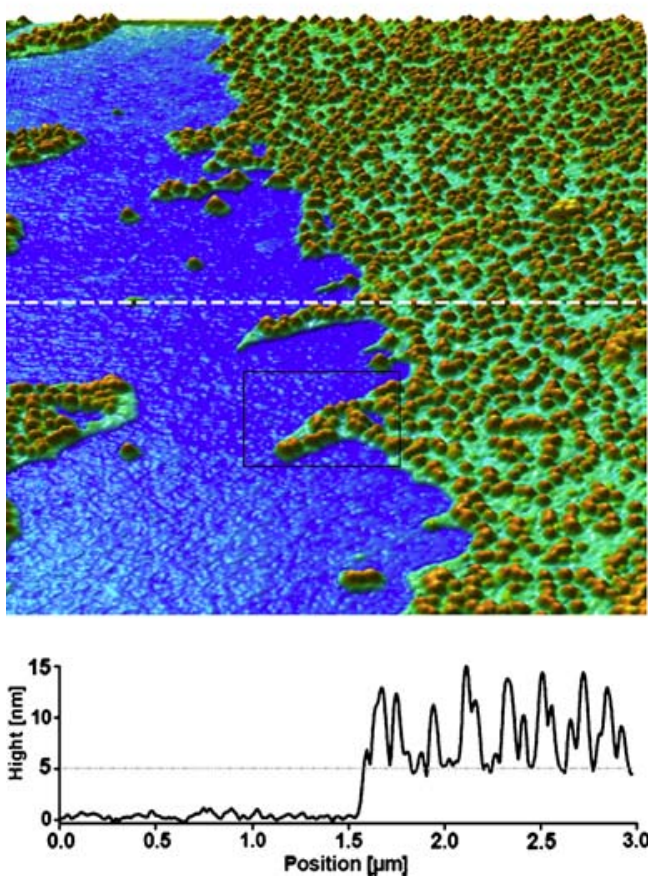

Fig. 6 3D color-coded view of a membrane fragment (cytosolic side) attached to poly-L-lysine-coated glass. Poly-L-lysine-coated glass is shown in blue, the lipid bilayer membrane is shown in turquoise, and the membrane proteins are shown in brown. The height profile along the broken line is presented in the lower part of the figure. The height of the lipid bilayer $(5 \mathrm{~nm})$ is indicated by the dotted line (modified from Schillers et al. [82])

lacking cytoskeletal-bound proteins. Instead of cytoskeleton, we found large areas of lipid membrane without any protruding proteins indicating a flow of lipids over the surface after isolation. It was shown that a phospholipid bilayer lacking proteins could be removed by repetitive scanning, whereas the lipid bilayer that contains proteins resists multiple scanning [83]. Figure 8 shows a complex scenario indicating high plasticity of plasma membranes. Large areas are free of protein, and membrane proteins firmly attached to poly-L-lysine coating surrounded by a ring of lipids can be observed. The lower part of Fig. 8 represents the height profile along the broken line. The lipid bilayer shows a height of about $5 \mathrm{~nm}$ with a rough surface and proteins protruding up to $15 \mathrm{~nm}$. Such a scenario is obviously caused by high mobility of the lipid bilayer. Membrane proteins need coating for attachment to glass, whereas lipid membrane components do not. An incomplete coating of the glass surface would therefore reduce the number of immobilized proteins, and we assume that the affinity of the phospholipids to uncoated glass is higher than the lipid affinity to poly-L-lysine. This apparently results in a flow of the lipid bilayer away from proteins (attached to poly-L-lysine) toward the naked glass. Figure 9 shows multiple planes of lipid bilayers lacking proteins in a lamellar arrangement. The lower part of Fig. 9 represents 


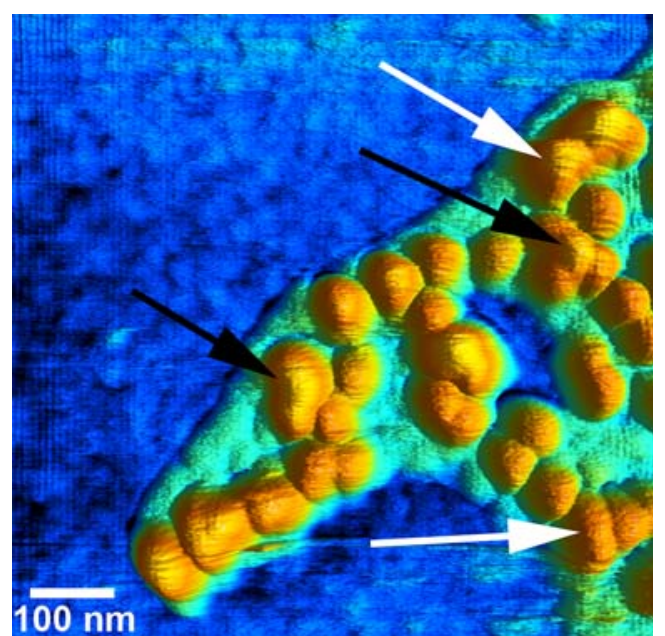

Fig. 7 High-resolution scan $(800 \times 800 \mathrm{~nm})$ of an edge of a membrane patch (marked area in Fig. 6). Proteins appear as structures with different height and shape. Some proteins apparently exhibit "shoulders" (white arrows), while others overlap (black arrows). The height scale is the same as in Fig. 6

the height profile along the broken line. The first plateau is a membrane of $5 \mathrm{~nm}$ in height (green), while the second plateau (lower part of the image) represents a second lipid bilayer (orange) on top of the former one (total height measured from the glass support $=10 \mathrm{~nm}$ ). A third phospholipid bilayer (total height in reference to glass surface $=15 \mathrm{~nm}$ ) is visible in the upper part of the image (yellow). Such a scenario is obviously caused by incomplete poly-L-lysine (blue) coating. Defects in the poly-L-
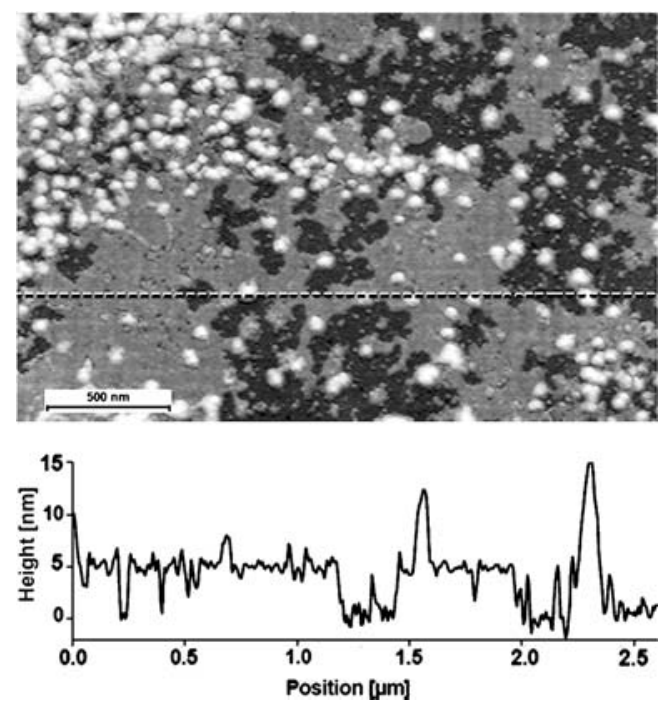

Fig. 8 AFM image of a highly fragmented lipid bilayer. This image shows glass surface (black), areas with protein-free lipids (gray), and isolated membrane proteins (white), firmly attached to the poly-Llysine coating. The lower part of this figure represents the height profile along the broken line. The lipid bilayer shows a height of about $5 \mathrm{~nm}$ with a rough surface and proteins protrude up to $15 \mathrm{~nm}$ from the surface
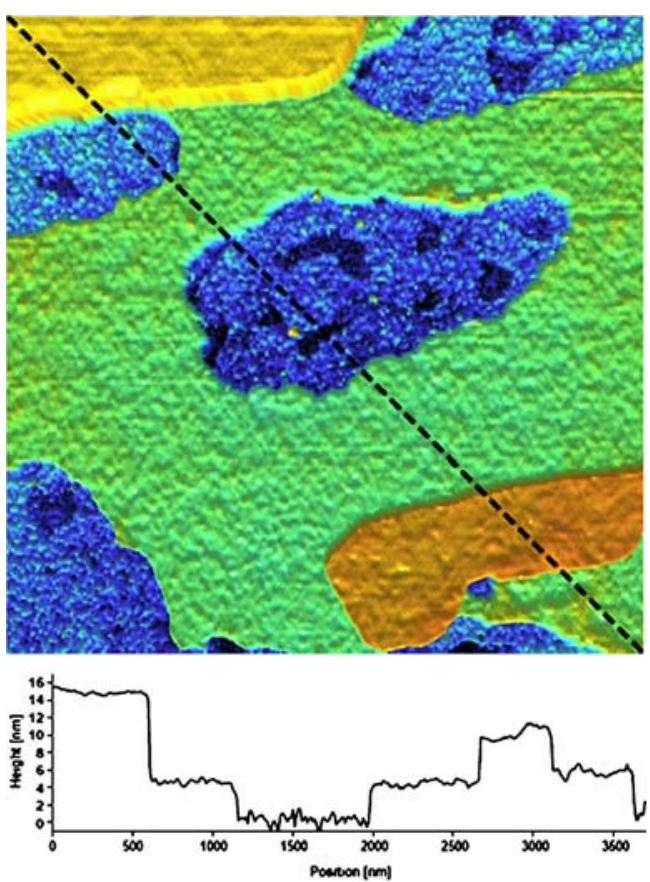

Fig. 9 Color-coded three-dimensional image of multiple planes of lipid bilayers lacking proteins in a lamellar arrangement. Black corresponds to glass surface and blue to poly-L-lysine coating. Green indicates the first lipid bilayer, orange the second bilayer on top of the former one, and finally, yellow corresponds to the third lipid bilayer. Defects in the poly-L-lysine coating (uncoated glass) are visible as dark holes in the blue surface. The profile along the broken line (lower part of Fig. 9) reveals height steps of $5 \mathrm{~nm}$ for each lipid bilayer

lysine coating (uncoated glass) are visible as dark holes in the blue surface.

It is interesting to note that we found no isolated proteins free of lipids. Single-isolated proteins are always surrounded by a skirt of lipids (Fig. 8). The hydrophobic interactions between phospholipids and proteins are usually strong enough to hold the lipids back. However, when membrane proteins occur at low density in the lipid membrane, hydrophobic interactions are too rare, and thus lipids flow off.

We assume that membrane proteins are necessary for stabilizing the lipid bilayer by hydrophobic interactions between phospholipids and transmembrane domains of the proteins. The lipid bilayer is stable only when protein density of the membrane is high. High protein density shields the lipid bilayer from applying lateral scanning forces caused by the AFM tip. The pure lipid component of the plasma membrane on the poly-L-lysine coating usually does not resist scanning. Derived from our observations, we postulate a minimum of four different forces that should be considered when the plasma membrane is attached to glass. One force is the (possibly electrostatic) attraction force between membrane proteins and poly-L-lysine (F1). A second force is the attraction force between the hydrophobic portions of the membrane proteins and the lipid bilayer 
(F2). An attraction force of similar magnitude is assumed to occur between the phospholipid bilayer and the naked glass surface (F3). Finally, a repelling rather than an attraction force is assumed to exist between the lipid bilayer and polyL-lysine (F4). Besides these four forces (F1 to F4), the density and intrinsic nature (size, glycosylation, electrical charges, etc) of the membrane proteins in the lipid bilayer determine whether a native plasma membrane can be successfully spread on glass or not.

\section{CFTR in the membrane of Xenopus laevis Oocytes}

The $X$. laevis oocyte is a commonly used expression system for human CFTR [24, 97, 107, 115]. Three days after injection of CFTR complementary ribonucleic acid, we examined the expression of CFTR with voltage clamp experiments. Only membranes of oocytes exhibiting IBMX (3-isobutyl-1-methylxanthine)-inducible currents in voltage clamp analysis were isolated and scanned by AFM $[1,28]$. Numerous studies have revealed that CFTR-mediated $\mathrm{Cl}^{-}$ secretion is regulated by modulating channel activity and by adjusting the total number of CFTR channels in the plasma membrane (reviewed in $[5,28]$ ). The latter is achieved by the removal (i.e., endocytosis) and the insertion (i.e., recycling) of CFTR channels into the plasma membrane [99]. We therefore expected the number of CFTR molecules in CFTR-expressing oocytes to increase upon stimulation. Figure 10 shows two membrane areas of CFTR-positive oocytes. The membrane patch shown in the upper part of Fig. 10 was isolated before cAMP stimulation; the membrane shown in Fig. 10b was isolated during cAMP stimulation. The main difference between cAMPstimulated and nonstimulated oocyte membrane is the protein density. Quantification of protein distribution is shown in Fig. 10c. Molecular volumes were estimated from protein heights measured by AFM $[45,86]$.

We found virtually no difference in the total number of proteins per $\mu \mathrm{m}^{2}$ for CFTR-negative and CFTR-positive oocytes without stimulation. A mean density of 200 proteins per $\mu \mathrm{m}^{2}$ in nonstimulated CFTR-positive and control (waterinjected $=$ CFTR-negative) oocyte membranes was found. CFTR-positive oocytes exhibit a prominent protein population with a height of $12 \mathrm{~nm}$ corresponding to $475 \mathrm{kDa}$. We assume that this protein population is most likely a protein multimere rather than a single protein. The molecular weight of mature glycosylated CFTR is $180 \mathrm{kDa}$ [58] corresponding to a height of $8.7 \mathrm{~nm}$. Therefore, the peak value of $475 \mathrm{kDa}$, as found in nonstimulated CFTR-positive oocytes, is unlikely to represent individual CFTR molecules. Because this peak at $475 \mathrm{kDa}$ does not appear in CFTR-negative oocytes, we assume that ist represents a CFTR-related multiprotein cluster.
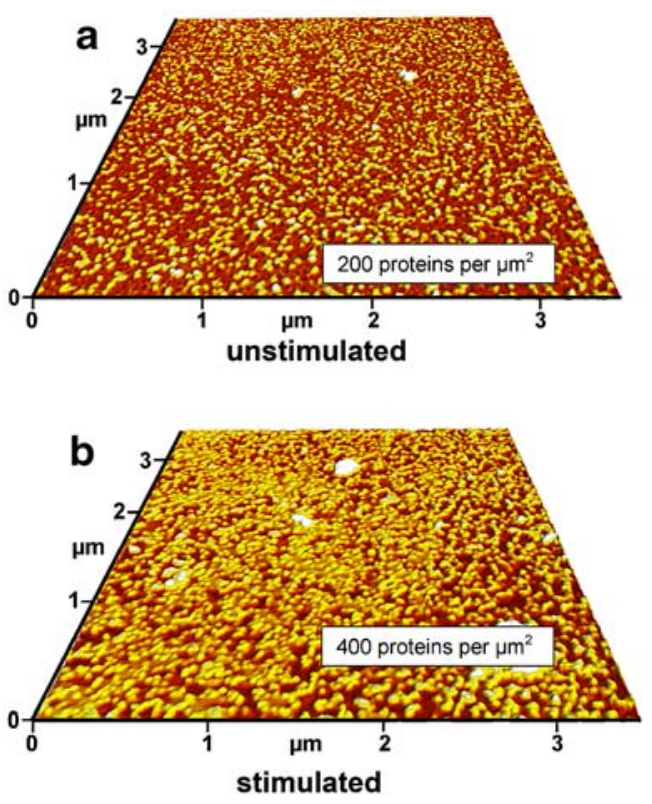

Mw [kDa]

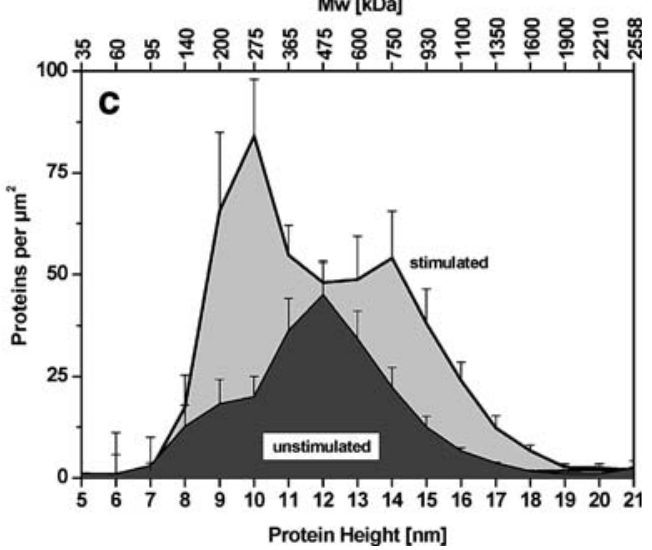

Fig. 10 Membrane patches of CFTR-expressing oocytes. The membrane patch shown in the upper part of Fig. 10 was isolated before cAMP stimulation (a), the membrane shown in $\mathbf{b}$ was isolated during cAMP stimulation. In this color-coded view, the plasma membrane, $5 \mathrm{~nm}$ in height, is shown in red. Proteins are shown with a color gradient from dark yellow to white, corresponding to heights from 6 to $20 \mathrm{~nm}$. The histogram (c) represents the protein height and molecular weight distribution of these plasma membranes. The distribution is shown in dark gray for nonstimulated oocytes and in light gray for stimulated oocytes, respectively (mean \pm SEM, $n=12$; modified from Schillers et al. [82])

Stimulation of CFTR-positive oocytes increases protein density in the plasma membrane, and the area covered by proteins, calculated from the histogram in Fig. 10c, increases in response to cAMP by about $110 \%$. This observation strongly suggests protein insertion into the plasma membrane. It was shown that plasma membrane capacitance, a quantitative measure for lipid bilayer membrane insertion, increases during cAMP-induced exocytosis in CFTR-positive oocytes but not in CFTR-negative oocytes [109]. In contrast, no significant change of membrane capacitance was observed upon stimulation of 
wtCFTR-overexpressing Chinese hamster ovary cells [34]. This leads to the assumption that the two mechanisms of CFTR activation (cAMP-induced CFTR insertion into the plasma membrane and cAMP-induced activation of dormant CFTR in the plasma membrane) are mutually not exclusive. It has been reported that both mechanisms of CFTR activation can simultaneously take place in oocytes [109]. The histogram of CFTR-positive oocytes shows two new peaks at 275 and $750 \mathrm{kDa}$ upon cAMP stimulation. Because both peaks do not appear in CFTR-negative oocytes in response to cAMP stimulation, we conclude that the two peaks are caused by CFTR. Considering the molecular mass of $180 \mathrm{kDa}$ for a CFTR monomer, the peak at 275 and $750 \mathrm{kDa}$ could be a multimeric CFTR or CFTR forming clusters with other proteins. Dimerization of CFTR, as derived from electrical experiments, has been reported recently [113]. Mature CFTR has a short residence time at the cell surface; it is endocytosed within several minutes, but then, most is recycled back into the plasma membrane $[52,72]$. It is conceivable that upon activation, oligomerization might prevent or diminish endocytosis and leave more active channels in the plasma membrane until dephosphorylation and inactivation have occurred [74].

Taken together, the data show that upon stimulation with cAMP, CFTR is inserted into the plasma membrane indicated by a shift in protein density and protein distribution. Insertion of CFTR in the plasma membrane leads to the formation of clusters, heteromeric structures composed of CFTR, and other proteins with yet unknown stoichiometry.

\section{Quaternary structure of CFTR}

Up to now it is unclear if CFTR forms a multimer of two or more CFTR polypeptides or that a single CFTR is shows the entire activity [74]. There is evidence for monomeric as well as for dimeric CFTR. Coimmunoprecipitation experiments show a monomeric CFTR [54], and also Chen et al. [15] observed that detergent-solubilized CFTR migrate as a monomer through a sucrose velocity gradient. In contrast, $\mathrm{Li}$ et al. found that CFTR has the approximate size of a dimer in sodium dodecyl sulfate-polyarcylamide gel electrophoresis velocity gradient centrifugation [49]. The heterogeneous gating modes of different CFTR channels in a patch were interpreted as cooperative interactions between them [41]. Freeze-fracture electromicroscopy of membranes of Xenopus oocytes in which CFTR was expressed revealed transmembrane domains with a crosssectional area that corresponds to a CFTR dimer [21]. From observations that expression of wild-type and mutant CFTR sequences linked in tandem resulted in channels with intermediate gating properties, Zerhausen et al. [113] also concluded that two CFTR polypeptides form a functional CFTR. Additionally, linking at least two CFTR molecules via cytoplasmic $\mathrm{C}$-terminal binding by CAP 70 potentiates CFTR chloride channel action [108].

Structure analyses of several $\mathrm{ABC}$ transporters report homodimeric structures in which monomers interact within the transmembrane domains and form a central pore or internal chamber open to the inner or outer leaflet between the two subunits constituting the homodimer [11, 12, 32, $50,76,85,102]$. Translocation starts with ATP binding and hydrolysis at the NBD sites, which causes a conformational change. Chemical energy is transmitted to the transmembrane domains and causes the "power stroke," a reorientation of the transmembrane helices that translocates the substrate from one side of the membrane to the other. This was shown in detail for lipid flipase MsbA from $E$. coli [12] and $\mathrm{BtuCD}$, an E. coli $\mathrm{ABC}$ transporter responsible for vitamin $B_{12}$ uptake [50]. CFTR can be best described as a hydrolyzable-ligand-gated channel [2]. How the ABC transporter structural architecture provides for such a hydrolyzable-ligand-gated channel is not yet fully understood but can be generally rationalized by recent advances in $A B C$ protein enzymology. Most significant was the proposal $[38,101]$ supported by substantial evidence [33, $40,57]$ that rather than each forming an individual site of ATP binding and hydrolysis, the two NBDs jointly contribute ligands to the two sites [14, 103]. It was shown that channel gating is also modulated through association of the CFTR C-terminal domain with $\mathrm{Na}^{+} / \mathrm{H}^{+}$exchanger regulatory factor $[43,73]$ and the CFTR-associated protein-70 (CAP70) [108]. These proteins interact with the CFTR C-terminal tail through a pair of PDZ (PSD-95/ Discs-large/ ZO-1) domains, and it is assumed that they activate the channel probably by inducing and/or stabilizing its dimerization. The only crystallographic studies of CFTR are the high-resolution structure of NBD1 of murine CFTR [48] and a low-resolution three-dimensional structure of the entire human protein [77]. The latter shows a monomeric organization of CFTR, but the possibility that purification and crystallization affects CFTR oligomeric behavior cannot be excluded. These data do not preclude the possibility of oligomer formation in vivo, particularly if the latter was mediated by intercalating proteins that do not copurify.

The ability of AFM to achieve a high resolution of protein structures was used to enlighten the question of CFTR's quaternary structure. Chasan et al. [13] scanned purified CFTR reconstituted in a lipid bilayer. An average spherical radius of approximately $15 \mathrm{~nm}$ and a height of $2 \mathrm{~nm}$ were found. From these data, the protein volume and molecular mass were calculated [82], rendering a molecular mass in the order of $320 \mathrm{kDa}$, which is equivalent to a dimer because monomeric CFTR has a molecular mass of $180 \mathrm{kDa}$. 


\section{Revealing the structure of CFTR in oocyte plasma membrane}

The long-standing dilemma whether the functional CFTR is a monomer or a dimmer has not been solved yet. Because the specific arrangement of CFTR in plasma membrane is crucially important for its regulatory function, clarification of this point should allow a better understanding of mechanisms and dynamics of CFTR-dependent processes. In a first step, we identified and localized CFTR with low resolution by immunostaining and fluorescence microscopy [84]. We observed an increase in CFTR in the plasma membrane $5 \mathrm{~min}$ after stimulation. These observations confirm previous work on cAMP-dependent CFTR trafficking $[3,110]$. Therefore, we performed our experiments with plasma membranes isolated $5 \mathrm{~min}$ after cAMP stimulation to achieve a high CFTR density in the plasma membrane. In the second step, we studied samples stained with primary and secondary antibodies against CFTR. To clearly detect the antibodies located on the cytoplasmic side of the plasma membrane, we used immuno-gold labeling of the secondary antibody. Figure 11 a shows a $1-\mu \mathrm{m}^{2}$ patch of plasma membrane excised from a cAMP-stimulated,
CFTR-expressing oocyte. The light structures on the surface correspond to the individual gold labels. The height of the gold particles is in the range of 10 to $15 \mathrm{~nm}$, while the respective width is sometimes more than $50 \mathrm{~nm}$. The latter number is an overestimate because of the AFM tip convolution [53]. Although the density of proteins in the plasma membrane is high and the shape of proteins varies considerably, we frequently discovered distinct circular structures in close vicinity to individual gold labels (see inset of Fig. 11a). Clearly, circular structures are often hidden by closely neighboring gold particles so that we could not detect a similar circular structure next to each gold particle.

Most frequently, we observed a crater-like structure with a central aperture and a surrounding fringe. The latter usually shows dipartite symmetry, with several structural subcomponents. Another interesting parameter we could derive from the images is the apparent depth of the centrally located pore (Fig. 11b). This aperture obviously penetrates the lipid bilayer. With reference to the lipid bilayer surface, we measured an apparent pore depth of $1.6 \mathrm{~nm}$ (Fig. 11c). This is clearly an underestimate because of technical reasons. The AFM tip cannot physically enter the aperture
Fig. 11 AFM image of insideout plasma membrane patch excised $5 \mathrm{~min}$ after cAMP stimulation from CFTR expressing Xenopus laevis oocyte (a). Bright particles (height $=10$ to $15 \mathrm{~nm}$ ) correspond to the gold labels of the secondary antibodies directed against CFTR primary antibodies. Gold labels are frequently found in association with ring-like structures (see inset). The arrow in the image of a single ring-like structure (b) indicates the cytoplasmic aperture of the central pore. The profile along the broken line in b is shown in c. The black line indicates the level of the lipid bilayer. The apparent pore penetrates at least $1.6 \mathrm{~nm}$ into the lipid bilayer (modified from Schillers et al. [84])
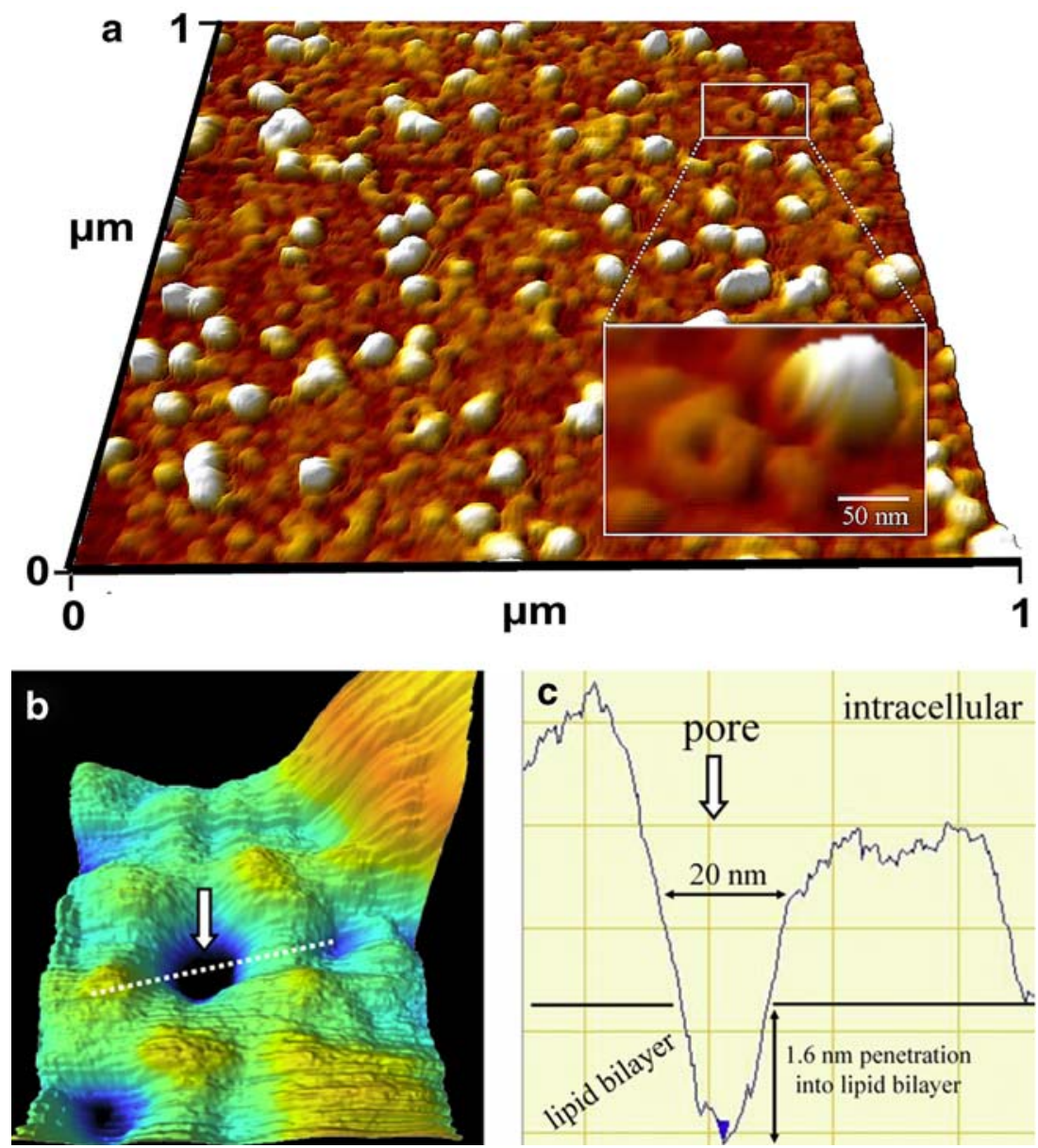
because of its pyramidal shape and its rather large dimensions. Thus, the pore penetrates the lipid bilayer (thickness $=5 \mathrm{~nm}$ ) most likely for more than $1.6 \mathrm{~nm}$. Figure 12a shows a twodimensional model of a single CFTR molecule, derived from the current literature. The dotted red line indicates the proposed profile when the AFM tip scans the substructural components of a CFTR molecule on the cytoplasmic surface. We should detect at least three substructures, NBD1 and NBD2 and the R-domain. We measured the individual heights of the substructures and calculated molecular volumes and molecular masses of the individual subunits. Although the scatter is large, there is reasonable agreement between the predicted dimensions of the substructural components and the measured values. Figure $12 \mathrm{c}$ integrates one half of the dimeric CFTR model into the AFM image. The $\mathrm{C}$ termini form a tail-by-tail outlet to which the primary antibody is bound. Then, the secondary antibody spans the short distance to the gold label. Starting from the $\mathrm{C}$ terminus, the NBD2 is the first structure detectable as a tiny protrusion. Then, the R-domain and the NBD1 follow. In between, we expect more or less coiled hydrophilic parts of the CFTR molecule, which possibly blur the images and reduce resolution of the larger substructures. The lipophilic portions of the CFTR molecule are rather buried in the bilayer, not accessible to the scanning AFM tip. Two such molecules form a CFTR as indicated in Fig. 12b. The two-dimensional structure of a single CFTR molecule follows the pattern of $\mathrm{NH}_{2}-(\mathrm{TM})_{6}-\mathrm{NBD} 1-\mathrm{R}-(\mathrm{TM})_{6}-\mathrm{NBD} 2-\mathrm{COOH}$. In our model, the two monomers are connected by TM6 and TM12, and the $\mathrm{N}$ terminus is placed between the R-domain and NBD1. It is worth mentioning that the calculated length of the protein chains [70] between the specific domains should indeed allow such arrangement, and that the function of TM6 and TM12 as well as of the N-tail support this model. It was shown that TM 6 and TM 12 are crucial for CFTR function [55, 56, 114] and make highly asymmetric contributions to the functional properties of the pore [29]. Carroll et al. [10] showed that a truncated CFTR, which contains TM5, TM6, and the second half of CFTR $(\Delta 259$ CFTR), has identical ion selectivity and single-channel conductance as compared to those to those of wild-type CFTR. The reason for this could be that the interaction of TM6 and TM12 leads to the formation of a functional CFTR dimer with the supposed arrangement. The $\mathrm{N}$ terminus is likely to play a crucial role in CFTR channel gating by binding to the R-domain and NBD1, most likely to the linker region (amino acids 595-740) [24, 62]. The R-domain and both NBDs have been reported to interact physically as well as functionally [51, 64]; these domains may act cooperatively to regulate CFTR channel gating. The $\mathrm{N}$ terminus
Fig. 12 a Two-dimensional model of a single CFTR molecule imbedded in the plasma membrane. The red dotted line indicates the profile drawn by an AFM tip. The 12 intramembrane helices cannot be detected by the AFM tip. The extramembrane domains NBD1, NBD2, and the R-domain are modeled as spheres with calculated diameters. b Model of a CFTR dimer in tail-to-tail configuration and one half of this model superimposed on the AFM image of a CFTR ring (c). The length of the extramembrane loops are drawn to scale. The transmembrane helices (TM) are numbered in the inset. The model assumes that the $\mathrm{N}$ terminus interacts with the Rdomain and may be flexible enough to interfere with ion channel gating at the pore entrance. The $\mathrm{C}$ termini form parallel structures at one end of the dimer interacting with the primary monoclonal antibody (modified from Schillers et al. [84])
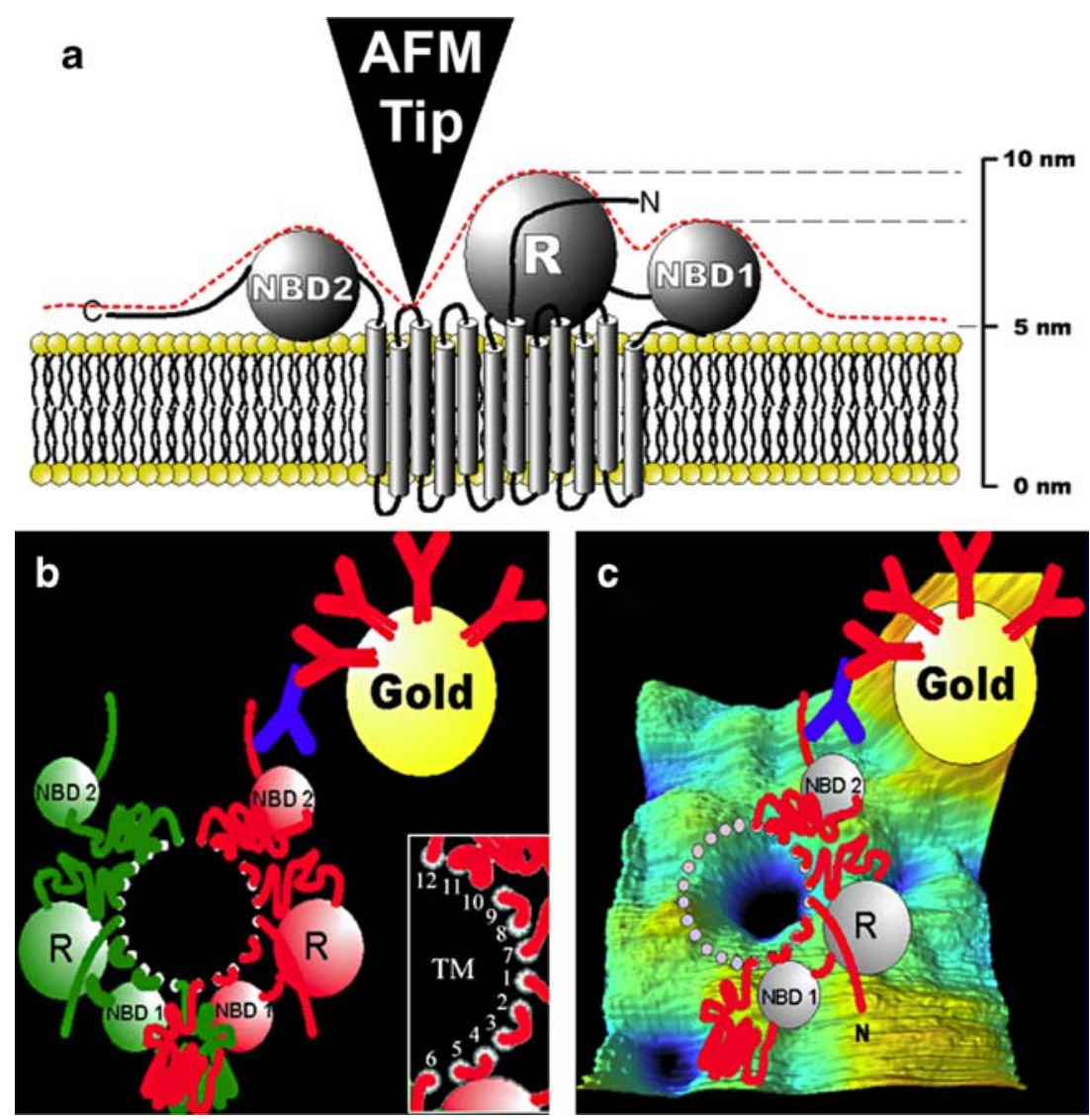
influences interactions between the phosphorylated Rdomain and NBDs $[24,62]$ and stabilizes CFTR channel activity by modulating interactions among these various domains. From the inspection of the AFM images, we postulate a mirror-image-like twofold symmetry of CFTR. Images support functional studies in which tail-to-tail dimerization is associated with highest chloride channel conductance. Tandem linkage of two CFTR molecules (i.e., head to tail dimerization) as proposed in other functional studies [108, 113] seems less likely because AFM images show mirror-image-like dimeric structures. A dominating characteristic of the AFM images is a single central pore. The translocation mechanism indicates that there are at least two different conformations of $\mathrm{ABC}$ transporters in native plasma membrane namely, open and closed states. That means that the central pore open chamber is visible or not. These two conformations were shown with electron microscopy in P-glycoprotein or multidrug resistance protein [47, $78,90]$. Because of our preparation (cAMP stimulation, etc.), we most likely imaged CFTR in an open state, but we cannot exclude any closed-state CFTR conformation in the same preparation.

We expected to find two gold particles at each CFTR ring but, surprisingly, found only some of the ring-like structures connected to two gold particles. We do not know whether it is technically more difficult to detect CFTR rings when two (instead of one) gold particles are in close vicinity or whether the second antibody gold-labeled complex has been sterically obstructed.

Taken together, our AFM studies revealed that CFTR expressed in Xenopus laevis oocytes forms a mirror-imagelike dimer with a twofold symmetry. This finding is in good correlation with studies in which tail-to-tail dimerization is associated with highest chloride channel conductance. Because intramolecular domains can be identified by AFM, it should be possible in the future to address the structural aspects of CFTR chloride channel regulation caused by interdomain interaction $[24,62]$.

\section{Conclusion}

The data presented in this review show unambiguously that isolation of plasma membrane on solid support is an advantageous way to study membrane proteins in their native environment with AFM. Investigation of CFTR with this technique reveals that human RBCs have a CFTR distribution comparable to that of epithelial cells as well as disclosing a reduced number of CFTR in cells derived from CF patients compared to healthy individuals. Application of AFM to isolated plasma membranes allows not only quantification of CFTR but also the study of CFTR dynamics. We showed that cAMP induces a rearrangement of membrane proteins in CFTR-expressing oocytes indicating the insertion of CFTR in the plasma membrane. This leads to the formation of clusters, heteromeric structures composed of CFTR, and other proteins with yet unknown stoichiometry. Derived from AFM molecular mass analysis of the intramolecular domains, the results indicate that two CFTR molecules line up in parallel, tail-to-tail, forming a pore in its center. This molecular arrangement could represent the CFTR chloride channel configuration, operative in native plasma membrane. Within these studies, we additionally observed that the plasma membrane is more a dense array of proteins with highly fluid lipids filling the space between them, than a solution of proteins in the viscous phospholipid bilayer.

Taken together, these studies on CFTR revealed that the combination of fluorescence microscopy and AFM allows not only the assessment of the number and localization of biologically important membrane proteins but could also provide unprecedented insight into their dynamics within the native membranes at a single-molecule level.

Acknowledgment This work was supported by the Deutsche Forschungsgemeinschaft, SFB 629, A6.

\section{References}

1. al-Awqati Q (1995) Regulation of ion channels by $A B C$ transporters that secrete ATP [comment]. Science 269:805-806

2. Aleksandrov AA, Aleksandrov LA, Riordan JR (2007) CFTR (ABCC7) is a hydrolyzable-ligand-gated channel. Pflugers Arch 453:693-702

3. Ameen NA, van Donselaar E, Posthuma G, de Jonge H, McLaughlin G, Geuze HJ, Marino C, Peters PJ (2000) Subcellular distribution of CFTR in rat intestine supports a physiologic role for CFTR regulation by vesicle traffic. Histochem Cell Biol 114:219-228

4. Bates IR, Hebert B, Luo Y, Liao J, Bachir AI, Kolin DL, Wiseman PW, Hanrahan JW (2006) Membrane lateral diffusion and capture of CFTR within transient confinement zones. Biophys J 91:1046-1058

5. Bertrand CA, Frizzell RA (2003) The role of regulated CFTR trafficking in epithelial secretion. Am J Physiol Cell Physiol 285: C1-18

6. Born M, Wolf E (1980) Principles of optics, 6th edn. Pergamon, New York

7. Bradbury NA (1999) Intracellular CFTR: localization and function. Physiol Rev 79:S175-S191

8. Braet F, Seynaeve C, de ZR, Wisse E (1998) Imaging surface and submembranous structures with the atomic force microscope: a study on living cancer cells, fibroblasts and macrophages. J Microsc 190:328-338

9. Braunstein GM, Roman RM, Clancy JP, Kudlow BA, Taylor AL, Shylonsky VG, Jovov B, Peter K, Jilling T, Ismailov II, Benos DJ, Schwiebert LM, Fitz JG, Schwiebert EM (2001) Cystic fibrosis transmembrane conductance regulator facilitates ATP release by stimulating a separate ATP release channel for autocrine control of cell volume regulation. J Biol Chem 276:6621-6630 
10. Carroll TP, Morales MM, Fulmer SB, Allen SS, Flotte TR, Cutting GR, Guggino WB (1995) Alternate translation initiation codons can create functional forms of cystic fibrosis transmembrane conductance regulator. J Biol Chem 270:11941-11946

11. Chami M, Steinfels E, Orelle C, Jault JM, Di Pietro A, Rigaud JL, Marco S (2002) Three-dimensional structure by cryo-electron microscopy of YvcC, an homodimeric ATP-binding cassette transporter from Bacillus subtilis. J Mol Biol 315:1075-1085

12. Chang G, Roth CB (2001) Structure of MsbA from E. coli: a homolog of the multidrug resistance ATP binding cassette (ABC) transporters. Science 293:1793-1800

13. Chasan B, Geisse NA, Pedatella K, Wooster DG, Teintze M, Carattino MD, Goldmann WH, Cantiello HF (2002) Evidence for direct interaction between actin and the cystic fibrosis transmembrane conductance regulator. Eur Biophys J 30:617624

14. Chen J, Lu G, Lin J, Davidson AL, Quiocho FA (2003) A tweezers-like motion of the ATP-binding cassette dimer in an ABC transport cycle. Mol Cell 12:651-661

15. Chen JH, Chang XB, Aleksandrov AA, Riordan JR (2002) CFTR is a monomer: biochemical and functional evidence. J Membr Biol 188:55-71

16. Cooper GM, Hausman RE (2006) The cell: a molecular approach, 4th edn. Sinauer, Sunderland, MA

17. Danker T, Oberleithner H (2000) Nuclear pore function viewed with atomic force microscopy. Pflugers Arch 439:671-681

18. Dupuit F, Kalin N, Brezillon S, Hinnrasky J, Tummler B, Puchelle E (1995) CFTR and differentiation markers expression in non-CF and delta F 508 homozygous CF nasal epithelium. J Clin Invest 96:1601-1611

19. Ehrenhofer U, Rakowska A, Schneider SW, Schwab A, Oberleithner H (1997) The atomic force microscope detects ATP-sensitive protein clusters in the plasma membrane of transformed MDCK cells. Cell Biol Int 21:737-746

20. Eppell SJ, Simmmons SR, Albrecht RM, Marchant RE (1995) Cell-surface receptors and proteins on platelet membranes imaged by scanning force microscopy using immunogold contrast enhancement. Biophys J 68:671-680

21. Eskandari S, Wright EM, Kreman M, Starace DM, Zampighi GA (1998) Structural analysis of cloned plasma membrane proteins by freeze-fracture electron microscopy. Proc Natl Acad Sci USA 95:11235-11240

22. Foster LJ, de Hoog CL, Mann M (2003) Unbiased quantitative proteomics of lipid rafts reveals high specificity for signaling factors. Proc Natl Acad Sci USA 100:5813-5818

23. Frizzell RA, Rechkemmer G, Shoemaker RL (1986) Altered regulation of airway epithelial cell chloride channels in cystic fibrosis. Science 233:558-560

24. Fu J, Ji HL, Naren AP, Kirk KL (2001) A cluster of negative charges at the amino terminal tail of CFTR regulates ATPdependent channel gating. J Physiol 536:459-470

25. Fuller CM, Benos DJ (1992) CFTR!. Am J Physiol 263:C267C286

26. Gadsby DC, Nagel G, Hwang TC (1995) The CFTR chloride channel of mammalian heart. Annu Rev Physiol 57:387-416

27. Giessibl FJ, Hembacher S, Bielefeldt H, Mannhart J (2000) Subatomic features on the silicon $(111)-(7 \times 7)$ surface observed by atomic force microscopy. Science 289:422-426

28. Guggino WB, Stanton BA (2006) New insights into cystic fibrosis: molecular switches that regulate CFTR. Nat Rev Mol Cell Biol 7:426-436

29. Gupta J, Evagelidis A, Hanrahan JW, Linsdell P (2001) Asymmetric structure of the cystic fibrosis transmembrane conductance regulator chloride channel pore suggested by mutagenesis of the twelfth transmembrane region. Biochemistry 40:6620-6627
30. Haws C, Finkbeiner WE, Widdicombe JH, Wine JJ (1994) CFTR in Calu-3 human airway cells: channel properties and role in cAMP-activated $\mathrm{Cl}^{-}$conductance. Am J Physiol 266:L502-L512

31. Haydon PC, Henderson E, Stanley ES (1994) Localization of individual calcium channels at the release face of a presynaptic nerve terminal. Neuron 13:1275-1280

32. Higgins CF, Linton KJ (2001) Structural biology. The xyz of ABC transporters. Science 293:1782-1784

33. Hopfner KP, Karcher A, Shin DS, Craig L, Arthur LM, Carney JP, Tainer JA (2000) Structural biology of Rad50 ATPase: ATPdriven conformational control in DNA double-strand break repair and the ABC-ATPase superfamily. Cell 101:789-800

34. Hug MJ, Thiele IE, Greger R (1997) The role of exocytosis in the activation of the chloride conductance in Chinese hamster ovary cells (CHO) stably expressing CFTR. Pflugers Arch 434:779-784

35. Jacobson K, Sheets ED, Simson R (1995) Revisiting the fluid mosaic model of membranes. Science 268:1441-1442

36. Jaiswal JK, Goldman ER, Mattoussi H, Simon SM (2004) Use of quantum dots for live cell imaging. Nat Methods 1:73-78

37. Jaiswal JK, Simon SM (2007) Imaging single events at the cell membrane. Nat Chem Biol 3:92-98

38. Jones PM, George AM (2002) Mechanism of ABC transporters: a molecular dynamics simulation of a well characterized nucleotidebinding subunit. Proc Natl Acad Sci USA 99:12639-12644

39. N, Claass A, Sommer M, Puchelle E, Tummler B (1999) DeltaF508 CFTR protein expression in tissues from patients with cystic fibrosis. J Clin Invest 103:1379-1389

40. Karpowich N, Martsinkevich O, Millen L, Yuan YR, Dai PL, MacVey K, Thomas PJ, Hunt JF (2001) Crystal structures of the MJ1267 ATP binding cassette reveal an induced-fit effect at the ATPase active site of an ABC transporter. Structure 9:571-586

41. Krouse ME, Wine JJ (2001) Evidence that CFTR channels can regulate the open duration of other CFTR channels: cooperativity. J Membr Biol 182:223-232

42. Kunzelman K, Kiser GL, Schreiber R, Riordan JR (1997) Inhibition of epithelial $\mathrm{Na}+$ currents by intracellular domains of the cystic fibrosis transmembrane conductance regulator. FEBS Lett 400:341-344

43. Ladias JA (2003) Structural insights into the CFTR-NHERF interaction. J Membr Biol 192:79-88

44. Lange T, Jungmann P, Haberle J, Falk S, Duebbers A, Bruns R, Ebner A, Hinterdorfer P, Oberleithner H, Schillers H (2006) Reduced number of CFTR molecules in erythrocyte plasma membrane of cystic fibrosis patients. Mol Membr Biol 23:1-7

45. Larmer J, Schneider SW, Danker T, Schwab A, Oberleithner H (1997) Imaging excised apical plasma membrane patches of MDCK cells in physiological conditions with atomic force microscopy. Pflugers Arch 434:254-260

46. Le Grimellec C, Lesniewska E, Cachia C, Schreiber JP, de Fornel F, Goudonnet JP (1994) Imaging of the membrane surface of MDCK cells by atomic force microscopy. Biophys J 67:36-41

47. Lee JY, Urbatsch IL, Senior AE, Wilkens S (2002) Projection structure of P-glycoprotein by electron microscopy. Evidence for a closed conformation of the nucleotide binding domains. J Biol Chem 277:40125-40131

48. Lewis HA, Buchanan SG, Burley SK, Conners K, Dickey M, Dorwart M, Fowler R, Gao X, Guggino WB, Hendrickson WA, Hunt JF, Kearins MC, Lorimer D, Maloney PC, Post KW, Rajashankar KR, Rutter ME, Sauder JM, Shriver S, Thibodeau PH, Thomas PJ, Zhang M, Zhao X, Emtage S (2004) Structure of nucleotide-binding domain 1 of the cystic fibrosis transmembrane conductance regulator. EMBO J 23:282-293

49. Li C, Roy K, Dandridge K, Naren AP (2004) Molecular assembly of cystic fibrosis transmembrane conductance regulator in plasma membrane. J Biol Chem 279:24673-24684 
50. Locher KP, Lee AT, Rees DC (2002) The E. coli BtuCD structure: a framework for $\mathrm{ABC}$ transporter architecture and mechanism. Science 296:1091-1098

51. Lu NT, Pedersen PL (2000) Cystic fibrosis transmembrane conductance regulator: the purified $\mathrm{NBF} 1+\mathrm{R}$ protein interacts with the purified NBF2 domain to form a stable NBF1+R/NBF2 complex while inducing a conformational change transmitted to the C-terminal region. Arch Biochem Biophys 375:7-20

52. Lukacs GL, Segal G, Kartner N, Grinstein S, Zhang F (1997) Constitutive internalization of cystic fibrosis transmembrane conductance regulator occurs via clathrin-dependent endocytosis und is regulated by protein phosphorylation. Biochem $\mathrm{J} 328$ (Pt 2):353-361

53. Markiewicz P, Goh MC (1995) Simulation of atomic force microscope tip-sample/sample-tip reconstruction. J Vac Sci Technol B 13:1115-1118

54. Marshall J, Fang S, Ostedgaard LS, O'Riordan CR, Ferrara D, Amara JF, Hoppe H, Scheule RK, Welsh MJ, Smith AE (1994) Stoichiometry of recombinant cystic fibrosis transmembrane conductance regulator in epithelial cells and its functional reconstitution into cells in vitro. J Biol Chem 269:2987-2995

55. McCarty NA (2000) Permeation through the CFTR chloride channel. J Exp Biol 203(Pt 13):1947-1962

56. McDonough S, Davidson N, Lester HA, McCarty NA (1994) Novel pore-lining residues in CFTR that govern permeation and open-channel block. Neuron 13:623-634

57. Moody JE, Millen L, Binns D, Hunt JF, Thomas PJ (2002) Cooperative, ATP-dependent association of the nucleotide binding cassettes during the catalytic cycle of ATP-binding cassette transporters. J Biol Chem 277:21111-21114

58. Moyer BD, Loffing J, Schwiebert EM, Loffing-Cueni D, Halpin PA, Karlson KH, Ismailov II, Guggino WB, Langford GM, Stanton BA (1998) Membrane trafficking of the cystic fibrosis gene product, cystic fibrosis transmembrane conductance regulator, tagged with green fluorescent protein in madin-darby canine kidney cells. J Biol Chem 273:21759-21768 (published erratum appears in J Biol Chem 1998 Oct 2;273(40):26256)

59. Muller DJ, Baumeister W, Engel A (1996) Conformational change of the hexagonally packed intermediate layer of Deinococcus radiodurans monitored by atomic force microscopy. J Bacteriol 178:3025-3030

60. Muller DJ, Sapra KT, Scheuring S, Kedrov A, Frederix PL, Fotiadis D, Engel A (2006) Single-molecule studies of membrane proteins. Curr Opin Struct Biol 16:489-495

61. Muller DJ, Schabert FA, Buldt G, Engel A (1995) Imaging purple membranes in aqueous solutions at sub-nanometer resolution by atomic force microscopy. Biophys $\mathrm{J}$ 68:16811686

62. Naren AP, Cormet-Boyaka E, Fu J, Villain M, Blalock JE, Quick MW, Kirk KL (1999) CFTR chloride channel regulation by an interdomain interaction. Science 286:544-548

63. Nechyporuk-Zloy V, Stock C, Schillers H, Oberleithner H, Schwab A (2006) Single plasma membrane $\mathrm{K}+$ channel detection by using dual-color quantum dot labeling. Am J Physiol Cell Physiol 291:C266-C269

64. Neville DC, Rozanas CR, Tulk BM, Townsend RR, Verkman AS (1998) Expression and characterization of the NBD1-R domain region of CFTR: evidence for subunit-subunit interactions. Biochemistry 37:2401-2409

65. Nikova D, Lange T, Oberleithner H, Schillers H, Ebner A, Hinterdorfer P (2006) Atomic force microscopy in nanomedicine. In: Bhushan B, Fuchs H, Hosaka S (eds) Applied scanning probe methods. Springer, New York, pp 1-31

66. Oberleithner $\mathrm{H}$ (2007) Is the vascular endothelium under the control of aldosterone? Facts and hypothesis. Pflugers Arch 454:187-193
67. Oberleithner H, Schillers H, Schneider SW, Henderson RM (2001) Nanoarchitecture of Plasma membrane visualized with atomic force microscopy. In: Lopatin A, Nichols CG (ed) Ion channel localization methods and protocols methods in pharmacology and toxicology. Humana, Totowa, NJ, pp 405-424

68. Oberleithner H, Schillers H, Wilhelmi M, Butzke D, Danker T (2000) Nuclear pores collapse in response to $\mathrm{CO}_{2}$ imaged with atomic force microscopy. Pflugers Arch 439:251-255

69. Oberleithner H, Schneider S, Bustamante JO (1996) Atomic force microscopy visualizes ATP-dependent dissociation of multimeric TATA-binding protein before translocation into the cell nucleus. Pflugers Arch 432:839-844

70. Oroudjev E, Soares J, Arcdiacono S, Thompson JB, Fossey SA, Hansma HG (2002) Segmented nanofibers of spider dragline silk: atomic force microscopy and single-molecule force spectroscopy. Proc Natl Acad Sci USA 99(Suppl 2):6460-6465

71. Papadopoulos V, Boujrad N, Ikonomovic MD, Ferrara P, Vidic B (1994) Topography of the Leydig cell mitochondrial peripheraltype benzodiazepine receptor. Mol Cell Endocrinol 104:R5-R9

72. Prince LS, Workman RB Jr, Marchase RB (1994) Rapid endocytosis of the cystic fibrosis transmembrane conductance regulator chloride channel. Proc Natl Acad Sci USA 91:51925196

73. Raghuram V, Mak DD, Foskett JK (2001) Regulation of cystic fibrosis transmembrane conductance regulator single-channel gating by bivalent PDZ-domain-mediated interaction. Proc Natl Acad Sci USA 98:1300-1305

74. Riordan JR (2005) Assembly of functional CFTR chloride channels. Annu Rev Physiol 67:701-718

75. Riordan JR, Rommens JM, Kerem B, Alon N, Rozmahel R, Grzelczak Z, Zielenski J, Lok S, Plavsic N, Chou JL (1989) Identification of the cystic fibrosis gene: cloning and characterization of complementary DNA. Science 245:1066-1073 (published erratum appears in Science 1989 Sep 29;245(4925):1437)

76. Rosenberg MF, Callaghan R, Ford RC, Higgins CF (1997) Structure of the multidrug resistance P-glycoprotein to $2.5 \mathrm{~nm}$ resolution determined by electron microscopy and image analysis. J Biol Chem 272:10685-10694

77. Rosenberg MF, Kamis AB, Aleksandrov LA, Ford RC, Riordan JR (2004) Purification and crystallization of the cystic fibrosis transmembrane conductance regulator (CFTR). J Biol Chem 279:39051-39057

78. Rosenberg MF, Velarde G, Ford RC, Martin C, Berridge G, Kerr ID, Callaghan R, Schmidlin A, Wooding C, Linton KJ, Higgins CF (2001) Repacking of the transmembrane domains of Pglycoprotein during the transport ATPase cycle. EMBO J 20:5615-5625

79. Rotsch C, Radmacher M (2000) Drug-induced changes of cytoskeletal structure and mechanics in fibroblasts: an atomic force microscopy study. Biophys J 78:520-535

80. Schabert FA, Henn C, Engel A (1995) Native Escherichia coli OmpF porin surfaces probed by atomic force microscopy. Science 268:92-94

81. Schafer C, Ludwig Y, Shahin V, Kramer A, Carl P, Schillers H, Oberleithner H (2007) Ethanol alters access to the cell nucleus. Pflugers Arch 453:809-818

82. Schillers H, Danker T, Madeja M, Oberleithner H (2001) Plasma membrane protein clusters appear in CFTR-expressing Xenopus laevis oocytes after cAMP stimulation. J Membr Biol 180:205-212

83. Schillers H, Danker T, Schnittler HJ, Lang F, Oberleithner H (2000) Plasma membrane plasticity of Xenopus laevis oocyte imaged with atomic force microscopy. Cell Physiol Biochem 10:99-107

84. Schillers H, Shahin V, Albermann L, Schafer C, Oberleithner H (2004) Imaging CFTR: a tail to tail dimer with a central pore. Cell Physiol Biochem 14:1-10 
85. Schmitt L, Tampe R (2002) Structure and mechanism of ABC transporters. Curr Opin Struct Biol 12:754-760

86. Schneider SW, Larmer J, Henderson RM, Oberleithner H (1998) Molecular weights of individual proteins correlate with molecular volumes measured by atomic force microscopy. Pflugers Arch 435:362-367

87. Schneider SW, Pagel P, Rotsch C, Danker T, Oberleithner H, Radmacher M, Schwab A (2000) Volume dynamics in migrating epithelial cells measured with atomic force microscopy. Pflugers Arch 439:297-303

88. Schneider SW, Sritharan KC, Geibel JP, Oberleithner H, Jena BP (1997) Surface dynamics in living acinar cells imaged by atomic force microscopy: identification of plasma membrane structures involved in exocytosis. Proc Natl Acad Sci USA 94:316-321

89. Schwiebert EM, Benos DJ, Egan ME, Stutts MJ, Guggino WB (1999) CFTR is a conductance regulator as well as a chloride channel. Physiol Rev 79:S145-S166

90. Seigneuret M, Garnier-Suillerot A (2003) A structural model for the open conformation of the mdr1 P-glycoprotein based on the MsbA crystal structure. J Biol Chem 278:30115-30124

91. Shahin V (2006) Route of glucocorticoid-induced macromolecules across the nuclear envelope as viewed by atomic force microscopy. Pflugers Arch 453:1-9

92. Singer SJ, Nicolson GL (1972) The fluid mosaic model of the structure of cell membranes. Science 175:720-731

93. Smith PR, Bradford AL, Schneider S, Benos DJ, Geibel JP (1997) Localization of amiloride-sensitive sodium channels in A6 cells by atomic force microscopy. Am J Physiol 272:C1295-C1298

94. Sprague RS, Ellsworth ML, Stephenson AH, Kleinhenz ME, Lonigro AJ (1998) Deformation-induced ATP release from red blood cells requires CFTR activity. Am J Physiol 275:H1726H1732

95. Stahlberg H, Fotiadis D, Scheuring S, Remigy H, Braun T, Mitsuoka K, Fujiyoshi Y, Engel A (2001) Two-dimensional crystals: a powerful approach to assess structure, function and dynamics of membrane proteins. FEBS Lett 504:166-172

96. Sterling KM Jr, Shah S, Kim RJ, Johnston NI, Salikhova AY, Abraham EH (2004) Cystic fibrosis transmembrane conductance regulator in human and mouse red blood cell membranes and its interaction with ecto-apyrase. J Cell Biochem 91:1174-1182

97. Stumpf A, Almaca J, Kunzelmann K, Wenners-Epping K, Huber SM, Haberle J, Falk S, Duebbers A, Walte M, Oberleithner H, Schillers H (2006) IADS, a decomposition product of DIDS activates a cation conductance in Xenopus oocytes and human erythrocytes: new compound for the diagnosis of cystic fibrosis. Cell Physiol Biochem 18:243-252

98. Stumpf A, Wenners-Epping K, Walte M, Lange T, Koch HG, Haeberle J, Duebbers A, Falk S, Kiesel L, Nikova D, Bruns R, Bertram H, Oberleithner H, Schillers H (2006) Physiological concept for a blood based CFTR test. Cell Physiol Biochem 17:29-36

99. Swiatecka-Urban A, Talebian L, Kanno E, Moreau-Marquis S, Coutermarsh B, Hansen K, Karlson KH, Barnaby R, Cheney RE, Langford GM, Fukuda M, Stanton BA (2007) Myosin Vb is required for trafficking of the cystic fibrosis transmembrane conductance regulator in Rab11a-specific apical recycling endosomes in polarized human airway epithelial cells. J Biol Chem 282:23725-23736

100. Swihart AH, Mikrut JM, Ketterson JB, Macdonald RC (2001) Atomic force microscopy of the erythrocyte membrane skeleton. J Microsc 204:212-225
101. Urbatsch IL, Gimi K, Wilke-Mounts S, Senior AE (2000) Conserved walker A Ser residues in the catalytic sites of Pglycoprotein are critical for catalysis and involved primarily at the transition state step. J Biol Chem 275:25031-25038

102. van Veen HW, Margolles A, Muller M, Higgins CF, Konings WN (2000) The homodimeric ATP-binding cassette transporter LmrA mediates multidrug transport by an alternating two-site (two-cylinder engine) mechanism. EMBO J 19:2503-2514

103. Verdon G, Albers SV, van ON, Dijkstra BW, Driessen AJ, Thunnissen AM (2003) Formation of the productive ATP$\mathrm{Mg} 2+$-bound dimer of GlcV, an ABC-ATPase from Sulfolobus solfataricus. J Mol Biol 334:255-267

104. Vereb G, Szollosi J, Matko J, Nagy P, Farkas T, Vigh L, Matyus L, Waldmann TA, Damjanovich S (2003) Dynamic, yet structured: The cell membrane three decades after the SingerNicolson model. Proc Natl Acad Sci USA 100:8053-8058

105. Verloo P, Kocken CH, Van Der WA, Tilly BC, Hogema BM, Sinaasappel M, Thomas AW, de Jonge HR (2004) Plasmodium falciparum-activated chloride channels are defective in erythrocytes from cystic fibrosis patients. J Biol Chem 279:1031610322

106. Voura EB, Jaiswal JK, Mattoussi H, Simon SM (2004) Tracking metastatic tumor cell extravasation with quantum dot nanocrystals and fluorescence emission-scanning microscopy. Nat Med 10:993-998

107. Wagner CA, Ott M, Klingel K, Beck S, Melzig J, Friedrich B, Wild KN, Broer S, Moschen I, Albers A, Waldegger S, Tummler B, Egan ME, Geibel JP, Kandolf R, Lang F (2001) Effects of the serine/threonine kinase SGK1 on the epithelial $\mathrm{Na}(+)$ channel $(\mathrm{ENaC})$ and CFTR: implications for cystic fibrosis. Cell Physiol Biochem 11:209-218

108. Wang S, Yue H, Derin RB, Guggino WB, Li M (2000) Accessory protein facilitated CFTR-CFTR interaction, a molecular mechanism to potentiate the chloride channel activity. Cell 103:169-179

109. Weber WM, Cuppens H, Cassiman JJ, Clauss W, Van Driessche W (1999) Capacitance measurements reveal different pathways for the activation of CFTR. Pflugers Arch 438:561-569

110. Weber WM, Segal A, Simaels J, Vankeerberghen A, Cassiman JJ, Van Driessche W (2001) Functional integrity of the vesicle transporting machinery is required for complete activation of cFTR expressed in Xenopus laevis oocytes. Pflugers Arch 441:850-859

111. Welsh MJ, Denning GM, Ostedgaard LS, Anderson MP (1993) Dysfunction of CFTR bearing the delta F508 mutation. J Cell Sci Suppl 17:235-239

112. Yamashina S, Katsumata $O$ (2000) Structural analysis of red blood cell membrane with an atomic force microscope. J Electron Microsc (Tokyo) 49:445-451

113. Zerhusen B, Zhao J, Xie J, Davis PB, Ma J (1999) A single conductance pore for chloride ions formed by two cystic fibrosis transmembrane conductance regulator molecules. J Biol Chem 274:7627-7630

114. Zhang ZR, Zeltwanger S, McCarty NA (2000) Direct comparison of NPPB and DPC as probes of CFTR expressed in Xenopus oocytes. J Membr Biol 175:35-52

115. Zhang ZR, Zeltwanger S, Smith SS, Dawson DC, McCarty NA (2002) Voltage-sensitive gating induced by a mutation in the fifth transmembrane domain of CFTR. Am J Physiol Lung Cell Mol Physiol 282:L135-L145 